\title{
Abnormal head posture due to gaze palsy can be corrected by eye muscle surgery
}

\section{Eye (2003) 17, 549. doi:10.1038/sj.eye.6700430}

Ophthalmologists have been rather slow to recognise that diplopia and abnormal head posture (AHP) owing to gaze palsy may be treated surgically. Publications on this subject have been sparse but recently the work of Schiavi and co-workers ${ }^{1}$ and Buckley and Elston ${ }^{2}$ and Spielmann $e t \mathrm{al}^{3}$ have drawn attention to this neglected area.

Most such patients have sustained either a CVA or a tumour, and many suffer from other disabilities in addition to diplopia and AHP and may be seen as a poor anaesthetic risk. It is important that ophthalmologists, neurologists, and neurosurgeons are aware that these patients may be treatable. Campos et al's $\mathrm{s}^{4}$ series of 13 patients with at least 2 years follow-up clearly shows the benefits that surgery can provide. If general anaesthetic is thought to be inadvisable, surgery can be performed under local anaesthetic. $^{2}$

The number of patients with these disorders is likely to be relatively small, but the implications are still important. Although ocular motility is not improved in these patients, the improvement in head posture without significant adverse effects may be attractive. This is a group of patients in whom the gaze palsy and AHP may have been accepted as part of their neurological disability, and thinking again about symptomatic treatment is appropriate.
R Harrad and I Ormerod

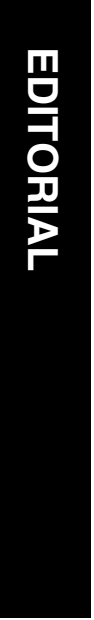

Careful patient selection for this procedure is important. Measurements should be stable for at least 1 year prior to surgery, and a trial of prisms preoperatively is useful in order to assess the potential benefits of surgery. Surgery comprises recession of yoke muscles in the direction of the AHP using the principle of the Anderson-Kestenbaum procedure or in vertical AHP bilateral recession of the appropriate vertical muscles. If necessary, recession can be enhanced or followed by resection of the antagonist muscles.

\section{References}

1 Schiavi C, Scorolli L, Campos EC. Surgical management of anomalous head posture due to supranuclear gaze palsies and acquired nystagmus. In: Spiritus M (ed). Transaction of the 23rd Meeting ESA, Nancy. 1996, pp 229-232.

2 Buckley SA, Elston J. Surgical Management of Supranuclear and internuclear ocular motility disorders. Eye 1997; 11: 377-380.

3 Spielmann A, Aflalo G, Spielmann AC. Surgery in vertical acquired strabismus. In: Lennerstrand $G$ (ed). Advances in Strabismology, Aeoleus Press: The Netherlands; 1999, pp 369-372.

4 Campos E, Schiavi C, Belusci C. Surgical management of anomalous head posture horizontal gaze palsy or acquired vertical nystasgmus. Eye, 17(5): 587-592
Bristol Eye Hospital Lower Maudlin Street Bristol BS1 2LX, UK

Correspondence:

R Harrad

Tel: + 44117928 4689;

Fax: + 441179284686

E-mail: r.a.harrad@

bristol.ac.uk

Received 11 June 2002 Accepted 20 October 2002 